\title{
Video Article \\ Synthesizing Sodium Tungstate and Sodium Molybdate Microcapsules via Bacterial Mineral Excretion
}

\author{
Pao-Hung Lin ${ }^{1}$, Ying-Tang Huang ${ }^{2}$, Fu-Wen Lin ${ }^{3}$ \\ ${ }^{1}$ Department of Electronic and Computer Engineering, National Taiwan University of Science and Technology \\ ${ }^{2}$ Department of Marine Biotechnology, National Kaohsiung Marine University \\ ${ }^{3}$ Institute of Applied English, National Taiwan Ocean University
}

Correspondence to: Pao-Hung Lin at plin21@mail.ntust.edu.tw

URL: https://www.jove.com/video/57022

DOI: doi:10.3791/57022

Keywords: Chemistry, Issue 131, Bacterial mineral excretion, microcapsules, sodium tungstate, sodium molybdate, nanoparticles, Shewanella algae, Pandoraea sp.

Date Published: 1/30/2018

Citation: Lin, P.H., Huang, Y.T., Lin, F.W. Synthesizing Sodium Tungstate and Sodium Molybdate Microcapsules via Bacterial Mineral Excretion. J. Vis. Exp. (131), e57022, doi:10.3791/57022 (2018)

\section{Abstract}

We present a method, the bacterial mineral excretion (BME), for synthesizing two kinds of microcapsules, sodium tungstate and sodium molybdate, and the two metal oxides' corresponding nanoparticles-the former being as small as $22 \mathrm{~nm}$ and the latter $15 \mathrm{~nm}$. We fed two strains of bacteria, Shewanella algae and Pandoraea sp., with various concentrations of tungstate or molybdate ions. The concentrations of tungstate and molybdate were adjusted to make microcapsules of different length-to-diameter ratios. We found that the higher the concentration the smaller the nanoparticles were. The nanoparticles came in with three length-to-diameter ratios: 10:1, 3:1 and 1:1, which were achieved by feeding the bacteria respectively with a low concentration, a medium concentration, and a high concentration. The images of the hollow microcapsules were taken via the scanning electron microsphere (SEM). Their crystal structures were verified by X-ray diffraction (XRD)-the crystal structure of molybdate microcapsules is $\mathrm{Na}_{2} \mathrm{MoO}_{4}$ and that of tungstate microcapsules is $\mathrm{Na}_{2} \mathrm{WO}_{4}$ with $\mathrm{Na}_{2} \mathrm{~W}_{2} \mathrm{O}_{7}$. These syntheses all were accomplished under a near ambient condition.

\section{Video Link}

The video component of this article can be found at https://www.jove.com/video/57022/

\section{Introduction}

Metal oxide nanoparticles are exploited for drug delivery ${ }^{1}$, construction artificial bones ${ }^{2}$, heterogeneous catalysis ${ }^{3}$, field emission ${ }^{4,5}$, solar $^{2}$ cells $^{6}$, gas sensors ${ }^{7}$, and lithium batteries ${ }^{8}$. For practical applications, the mechanical strength of both nanocrystals and their microstructure are crucial. Among the microstructures, hollow shell structures can be used to create lightweight, mechanically robust materials ${ }^{9}$. Among hollow shell structures, a spherical shape is known to be more rigid than an ellipsoidal shape; the latter has a larger length-to-diameter ratio than the former ${ }^{10,11}$. This work describes a protocol for synthesizing spherical microcapsules via bacteria with a non-toxic method under an ambient condition, which contrasts with the alternative methods, including the template synthesis method ${ }^{12}$, ultrasonic-spray-assisted synthesis method ${ }^{13}$ and hydrothermal method ${ }^{14}$. Some of the alternative methods require templates ${ }^{12}$, some a temperature as high as $500{ }^{\circ} \mathrm{C}^{13}$, and some a high pressure $^{14}$. As for the resulting structure, the template synthesis method utilizing the yeast template brings about a core-shell structure ${ }^{15}$, instead of one with a single wall, and the one utilizing the $\mathrm{E}$. coli template produces a structure with length-to-diameter ratio of 1.7:0.8, and is not spherical. $^{16}$.

In this work, we have made metal oxide microcapsules with a single wall and of spherical shape under an ambient condition by exploiting bacterial metabolism. In bacterial glycolysis, a chemical process that metabolizes carbon sources, like glucose and lactose, carbon sources are considered to be the origin of the reducing power generated therein. We manipulated bacterial metabolism by adjusting the concentration of carbon sources to achieve desired ends. This method is environment-friendly, using non-toxic agents and consuming much less electricity power. Lastly, this method allows the mass production of microcapsules simply by increasing the volume of broth.

Prior to the method, there have been another two methods utilizing bacterial metabolism to make minerals: biologically induced mineralization $(\mathrm{BIM})^{17}$ and biologically controlled mineralization (BCM) ${ }^{18}$. Neither BIM nor BCM can be used for making sodium tungstate and molybdate tungstate microcapsules like our process, which is designated as the bacterial mineral excretion (BME) ${ }^{19}$. In this experiment, the shape of microcapsules can be controlled to have a length-to-diameter ratio from 10:1 to 1:1, and the size of nanoparticle grains that form the shells can be adjusted ranging from $15 \mathrm{~nm}$ to $110 \mathrm{~nm}$. 


\section{Protocol}

Caution: Use latex gloves, protective eyeglasses, and a laboratory coat for performing the experiment. Whenever using the biosafety cabinet, turn on the cabinet fan and keep the cabinet door half-closed.

\section{Preparation of Glass Beads}

1. Place 100 glass beads of $3 \mathrm{~mm}$ diameter in a $100-\mathrm{mL}$ laboratory bottle, and then cap it tightly.

2. Autoclave the contents at $120^{\circ} \mathrm{C}$ for $10 \mathrm{~min}$.

3. Leave the bottle to cool down to room temperature, then place it in the biosafety cabinet.

\section{Preparation of Lysogeny Broth (LB)}

1. Dissolve $8 \mathrm{~g}$ powder of LB-Lennox broth in a $500-\mathrm{mL}$ laboratory bottle with $400 \mathrm{~mL}$ of water.

2. Stir the contents with a PTFE magnetic stirring bar for $20 \mathrm{~min}$, and then cap it tightly.

3. Autoclave the contents at $120^{\circ} \mathrm{C}$ for $10 \mathrm{~min}$.

4. Leave the solution to cool down to room temperature and place it in the biosafety cabinet.

5. Using a pipette, aliquot the broth into eight $15-\mathrm{mL}$ centrifuge tubes in the biosafety cabinet ( $12.5 \mathrm{~mL}$ each).

6. Aliquot the remaining broth into three $100-\mathrm{mL}$ laboratory bottles in the biosafety cabinet ( $100 \mathrm{~mL}$ each). Cap the three bottles tightly. Keep them in the biosafety cabinet.

\section{Culture of Shewanella algae}

1. Use the deep-frozen cryopreserved strain.

2. In the biosafety cabinet, pick out $1 \mathrm{~mL}$ of the frozen material from the frozen tube with a stainless-steel spatula, and place it into a centrifuge tube prepared in step 3.5 .

3. Incubate the cultures for $24 \mathrm{~h}$ in a $37^{\circ} \mathrm{C}$ incubator.

\section{Preparation of LB-Lennox (Broth with Agar) Petri Dishes}

1. Dissolve two tablets of LB-Lennox (broth with agar) into a $100-\mathrm{mL}$ laboratory bottle with $100 \mathrm{~mL}$ of water.

2. Stir the contents with a PTFE magnetic stirring bar for $20 \mathrm{~min}$ and then cap it tightly.

3. Autoclave the contents at $120^{\circ} \mathrm{C}$ for $10 \mathrm{~min}$.

4. In the biosafety cabinet, aliquot by hand $100 \mathrm{~mL}$ of solution into 4 Petri dishes, ensuring each receive $\sim 25 \mathrm{~mL}$. Leave the solution to cool down to room temperature.

\section{Preparation of Monoclonal Bacteria}

1. In the biosafety cabinet, label the three bottles prepared in step $2.6, \# 1, \# 2$ and \#3, respectively.

2. Pipette $0.1 \mathrm{~mL}$ of the resultant bacterial suspension in step 3.3 into bottle \#1. Cap the bottle and swing it by hand for $1 \mathrm{~min}$ to get a homogenous solution.

3. Pipette $0.1 \mathrm{~mL}$ of the resultant bacterial liquid in step 5.2 into bottle \#2. Cap the bottle and swing it by hand for $1 \mathrm{~min}$ to get a homogenous solution.

4. Pipette $0.1 \mathrm{~mL}$ of the resultant bacterial liquid in step 5.3 into bottle \#3. Cap the bottle and shake it by hand for $1 \mathrm{~min}$ to get a homogenous solution.

5. Pipette the liquid in bottle \#3 into the 4 Petri dishes prepared in step 4.4 , using a volume of $0.02 \mathrm{~mL}$ each.

6. Put the glass beads prepared in step 1.3 into the 4 Petri dishes used, 4 beads in each dish.

7. Close the lids of the Petri dishes and shake them by hand for $1 \mathrm{~min}$.

8. Turn the Petri dishes upside down and incubate in a $37^{\circ} \mathrm{C}$ incubator for $24 \mathrm{~h}$.

\section{Multiplication of Monoclonal Bacteria}

1. Fetch 7 tubes prepared in step 2.5 .

2. Pick out the resultant monoclonal bacteria from the 4 Petri dishes prepared in step 5.8 with a stainless steel-spatula, and put them into 7 tubes separately.

3. Leave the 7 tubes in a $37^{\circ} \mathrm{C}$ incubator for $24 \mathrm{~h}$.

4. Pick out the one with the largest light scattering using the visual colorimetric method.

\section{Preparation of LB-Lennox Broth with Glucose and Salt}

1. Put $10 \mathrm{~g}$ of LB-Lennox broth, $10 \mathrm{~g}$ of $\mathrm{NaCl}$, and $10 \mathrm{~g}$ of glucose into a $500-\mathrm{mL}$ laboratory bottle. Add water until the volume reaches $450 \mathrm{~mL}$.

2. Stir the contents with a PTFE magnetic stirring bar for $20 \mathrm{~min}$.

3. Autoclave the contents at $120^{\circ} \mathrm{C}$ for $10 \mathrm{~min}$. 


\section{Preparation of Sodium Tungstate}

1. Put $16.5 \mathrm{~g}$ of Sodium Tungstate $\mathrm{Na}_{2} \mathrm{WO}_{4} \# 2 \mathrm{H}_{2} \mathrm{O}$ into a $100-\mathrm{mL}$ laboratory bottle with a stainless-steel spatula. Add water until the volume reaches $50 \mathrm{~mL}$.

2. Stir the contents with a PTFE magnetic stirring bar for $20 \mathrm{~min}$.

3. Autoclave the contents at $120^{\circ} \mathrm{C}$ for $10 \mathrm{~min}$.

4. In the biosafety cabinet, get filtrate via a vacuum fiberglass filter with pores of $1 \mu \mathrm{m}$.

\section{Preparation of LB with Glucose, Salt, and Sodium Tungstate}

1. In the biosafety cabinet, pour the filtrate gained in step 8.4 by hand into the solution with glucose and salt prepared in step 7.3 .

2. In the biosafety cabinet, aliquot with a pipette the $500 \mathrm{~mL}$ resultant solution in step 9.1 into $10 \times 50 \mathrm{~mL}$ centrifuge tubes.

\section{Culture of Bacteria}

1. In the biosafety cabinet, fetch the liquid prepared in step 6.4 and aliquot it with a pipette into the 10 test tubes prepared in step 9.2 , with each tube receiving $0.05 \mathrm{~mL}$.

2. Incubate the 10 tubes in a $37^{\circ} \mathrm{C}$ incubator for $120 \mathrm{~h}$

\section{Harvest of BME minerals}

1. Ultrasonicate each of the 10 tubes in step 9.2 at $20 \mathrm{KHz}$ with $150 \mathrm{~W}$ for $1 \mathrm{~h}$.

2. Centrifuge the tubes at $2,025 \mathrm{xg}$ for $1 \mathrm{~h}$.

3. Remove the clear liquid in the tubes with a pipette, add water, and then repeat steps 11.1 and 11.2 one more time.

4. Remove the clear liquid in the tubes with a pipette, add alcohol, and then ultrasonicate them at $20 \mathrm{KHz}$ with $150 \mathrm{~W}$ for $1 \mathrm{~h}$.

5. Centrifuge the tubes at $2,025 \times \mathrm{g}$ for $1 \mathrm{~h}$.

6. Repeat steps 11.4 and 11.5 one more time

7. Harvest BME minerals by removing the clear liquid in the tubes with a pipette; afterwards, immediately cap the tubes without running any drying process.

\section{Oscillating Temperature with Pandoraea sp. and Molybdate}

1. Culture Pandoraea sp. in the same way as in steps $2,3,4,5$, and 6 for Shewanella algae. The result of this step corresponds to that of step 6.4 .

2. Make LB broth with both glucose and salt in the same way as in steps 7,8 , and 9 , except that the $16.5 \mathrm{~g}$ of sodium tungstate in step 7.1 is replaced with $12 \mathrm{~g}$ of sodium molybdate, $\mathrm{Na}_{2} \mathrm{MoO}_{4} \cdot 2 \mathrm{H}_{2} \mathrm{O}$. The result of this step corresponds to that of step 9.2.

3. In the biosafety cabinet, fetch the liquid prepared in step 12.1, and aliquot it with a pipette into the 10 tubes prepared in step 12.2 , with each tube receiving $0.05 \mathrm{~mL}$.

4. Incubate the 10 tubes in step 12.3 under oscillating temperatures for $120 \mathrm{~h}$ in a reciprocal shaking bath, oscillating the temperature 5 times between $25^{\circ} \mathrm{C}$ and $37^{\circ} \mathrm{C}$, with each temperature lasting for $12 \mathrm{~h}$.

\section{Representative Results}

Figure 1 shows genuine spherical microcapsules. Both the two strains of bacterium, Shewanella algae and Pandoraea sp., originally have a length-to-diameter ratio of 3:1. For achieving the length-to-diameter ratio of 1:1, a high concentration (>100 mM) of metal oxyanions is required A low concentration $(<5 \mathrm{mM})$ of oxyanions can result in a length to diameter ratio of 10:1, as that in Figure 2, which may result from the influx of the oxyanions, blocking the binary fission of bacteria. Lastly, for achieving a length-to-diameter ratio of 3:1, like that in Figure 3, a medium concentration $(\sim 20 \mathrm{mM})$ of oxyanions is needed. The formation of spherical shells, with a length-to-diameter ratio of $1: 1$, may be brought about by bacterial drives that make themselves shrink their surface area to balance the intake of oxyanions while diffusing oxyanions through the cell membrane. The three figures together indicate the length-to-diameter ratio may be tuned to from 10:1 to $1: 1$ simply by adjusting the concentration of oxyanions.

Figure 4 and Figure 5 show the nanoparticle grains of sodium molybdate in different sizes: the smaller one being $15 \mathrm{~nm}$, and the larger one $110 \mathrm{~nm}$. Note that in Figure 5, on the non-shattered shells, particles of $110 \mathrm{~nm}$ can still be chained up to each other, forming porous shells. The larger one was gained through oscillating the temperature of the culturing broth 5 times between $25^{\circ} \mathrm{C}$ and $37^{\circ} \mathrm{C}$, with each temperature lasting for $12 \mathrm{~h}$. During the temperature oscillation, grains of different sizes can not only be produced but also maintain the micro-spherical structure, which means we can make microcapsules with different grain sizes, from $15 \mathrm{~nm}$ to $110 \mathrm{~nm}$, just by controlling the broth temperature.

Figure 6 shows the broken wall with larger grains staying next to the opening of the wall. The wall thickness is about $22 \mathrm{~nm}$ and the larger grain is about $40-60 \mathrm{~nm}$. The difference in size may result from different metabolic processes, which are not yet identified. 


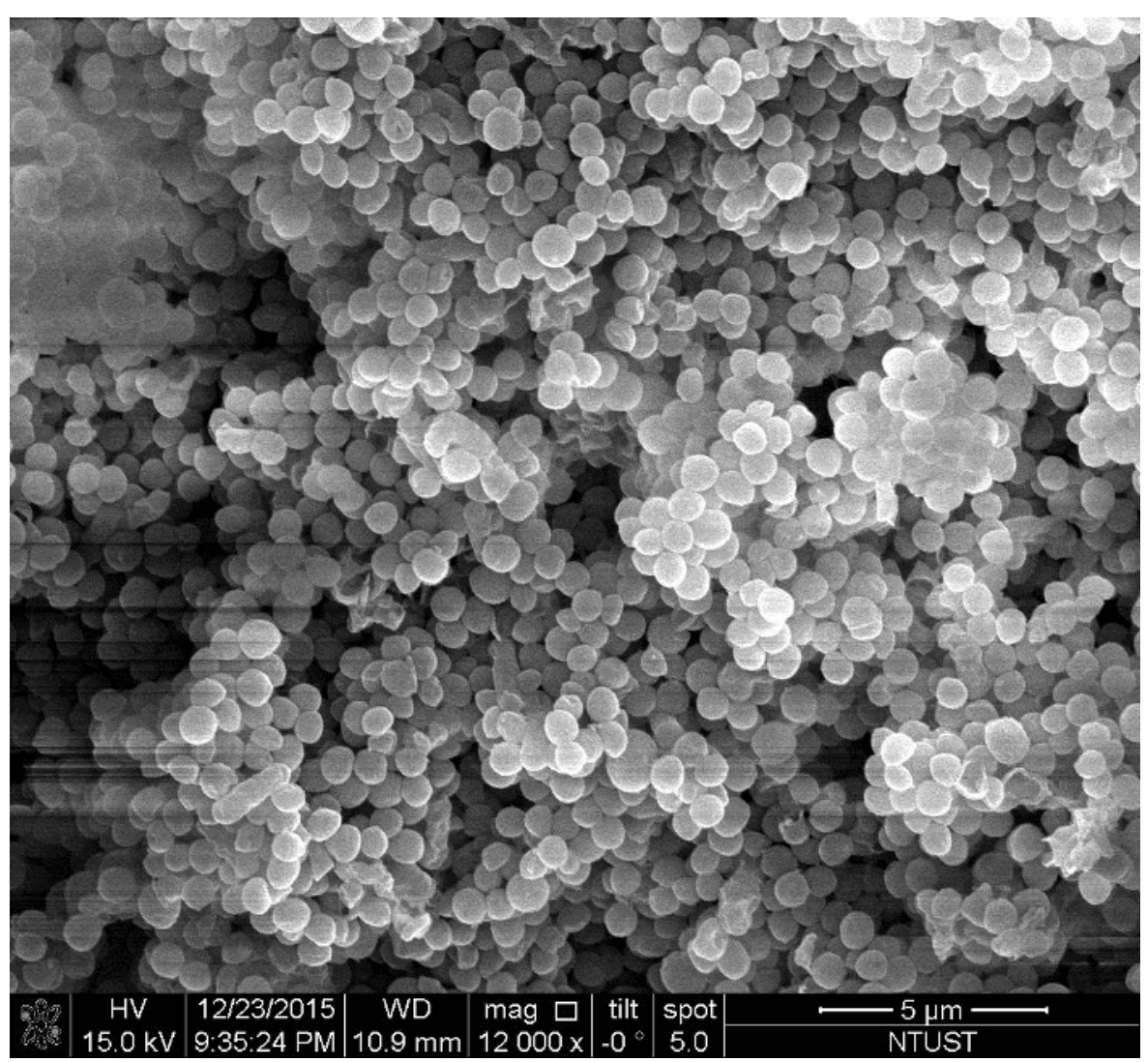

Figure 1: The SEM image of hollow spherical shells with a length-to-diameter ratio of 1:1. This structure was made of sodium tungstate excreted by Shewanella algae with glucose as the carbon source. Reprinted with permission from ECS J. of Solid State Sci. and Tech., 6(3), N3113 (2017). Copyright 2017, The Electrochemical Society. Please click here to view a larger version of this figure. 


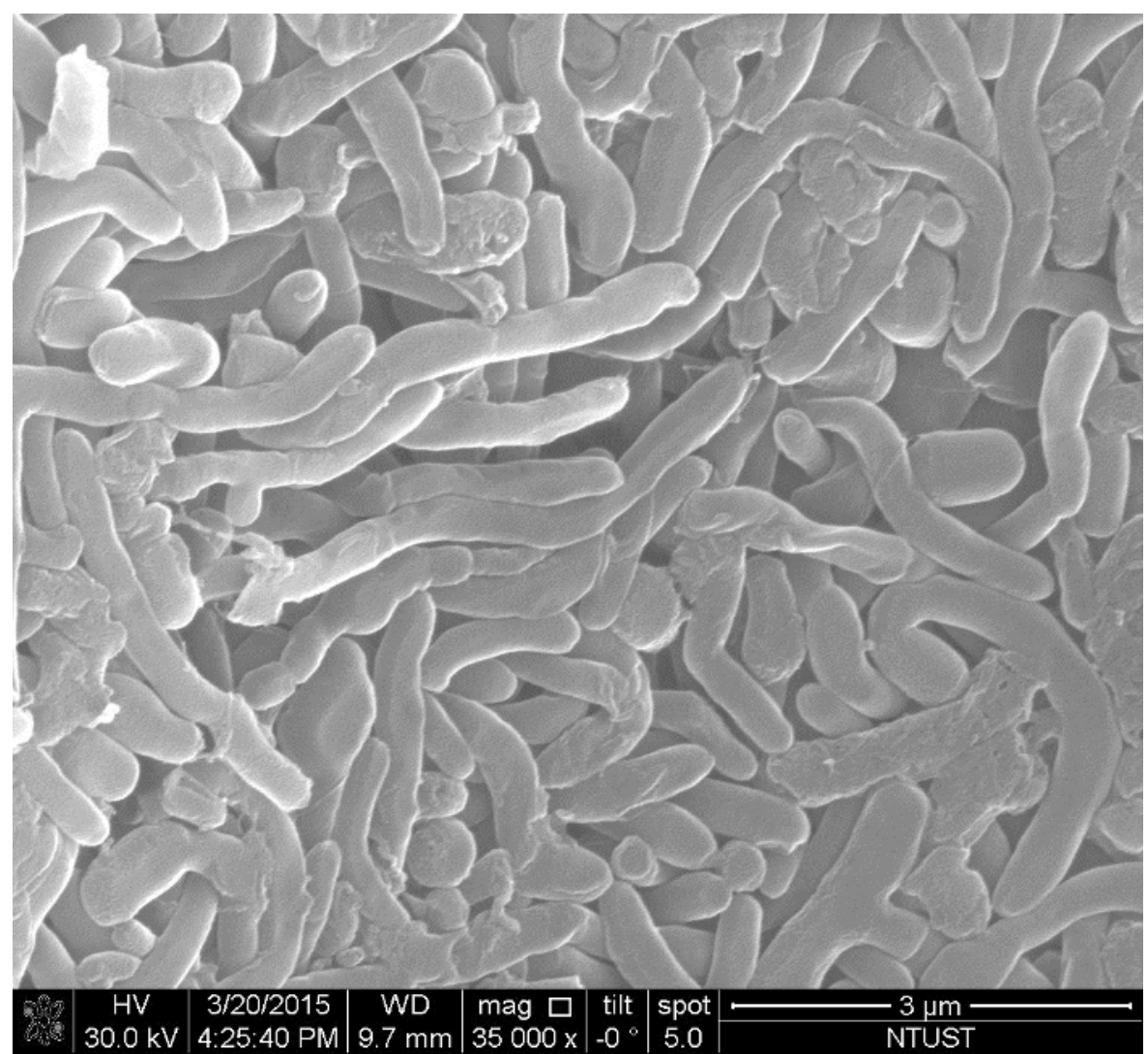

Figure 2: The SEM image of hollow long filament shells with a length-to-diameter ratio of 10:1. This structure was made of sodium molybdate excreted by Pandoraea sp. with glucose as the carbon source. Reprinted with permission from ECS J. of Solid State Sci. and Tech., 6(3), N3113 (2017). Copyright 2017, The Electrochemical Society. Please click here to view a larger version of this figure. 


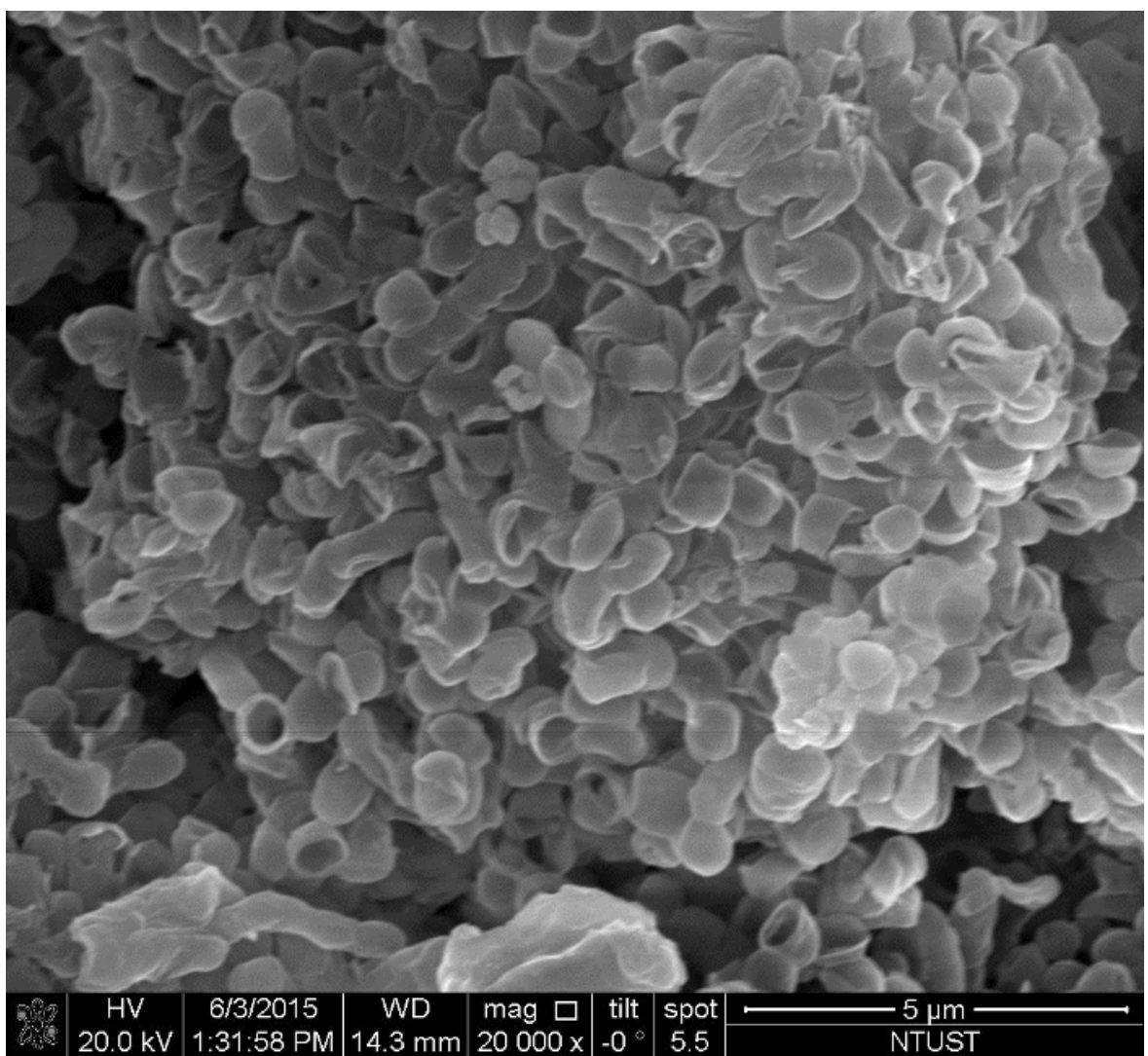

Figure 3: The SEM image of broken hollow rod-shaped shells with a length-to-diameter ratio of 3:1. This structure was made of sodium tungstate excreted by Shewanella algae with glucose as the carbon source. Reprinted with permission from ECS J. of Solid State Sci. and Tech., 6(3), N3113 (2017). Copyright 2017, The Electrochemical Society. Please click here to view a larger version of this figure. 


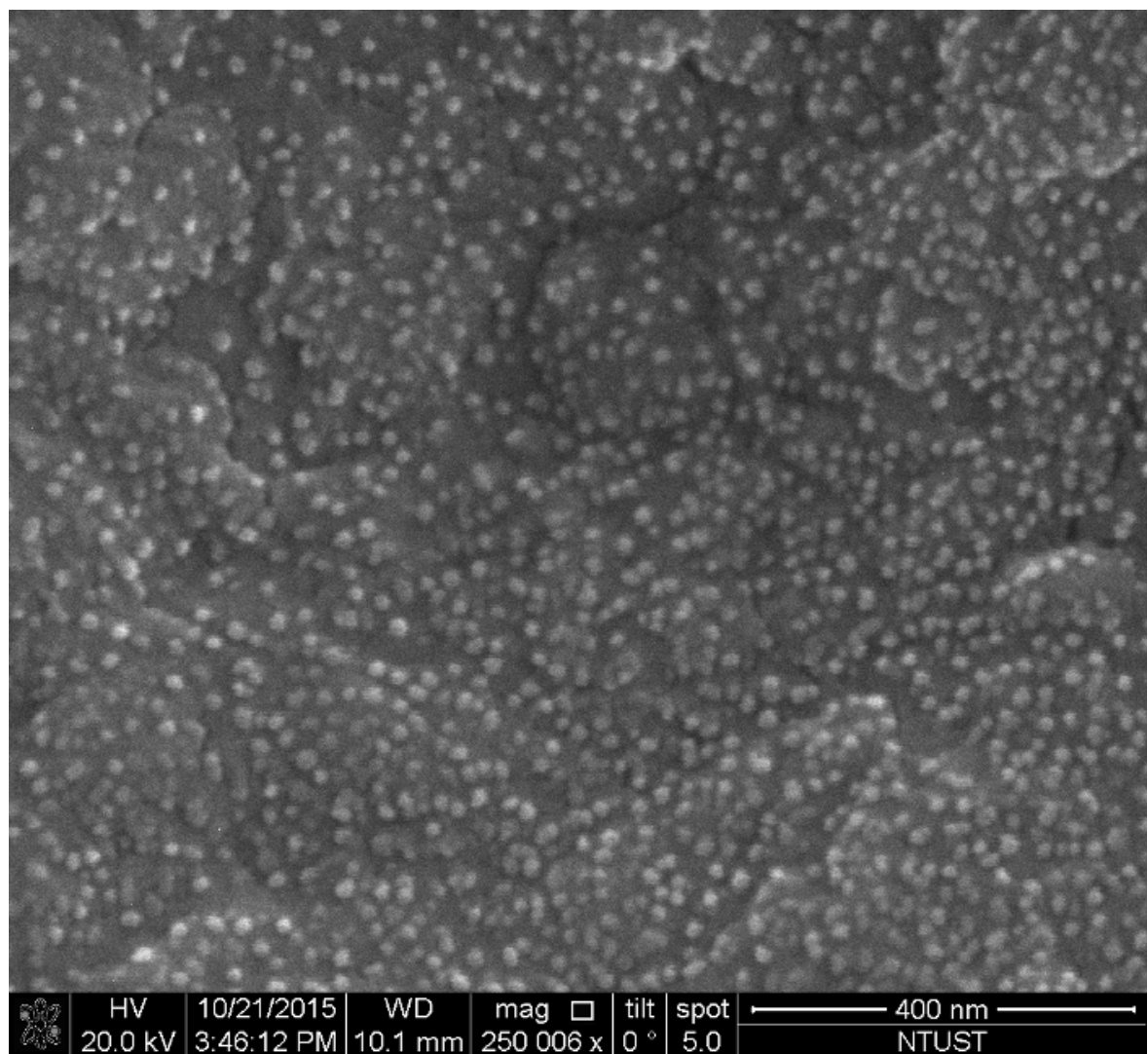

Figure 4: The SEM image of shattered sodium molybdate shells with a grain particle size of $15 \mathrm{~nm}$. Please click here to view a larger version of this figure. 


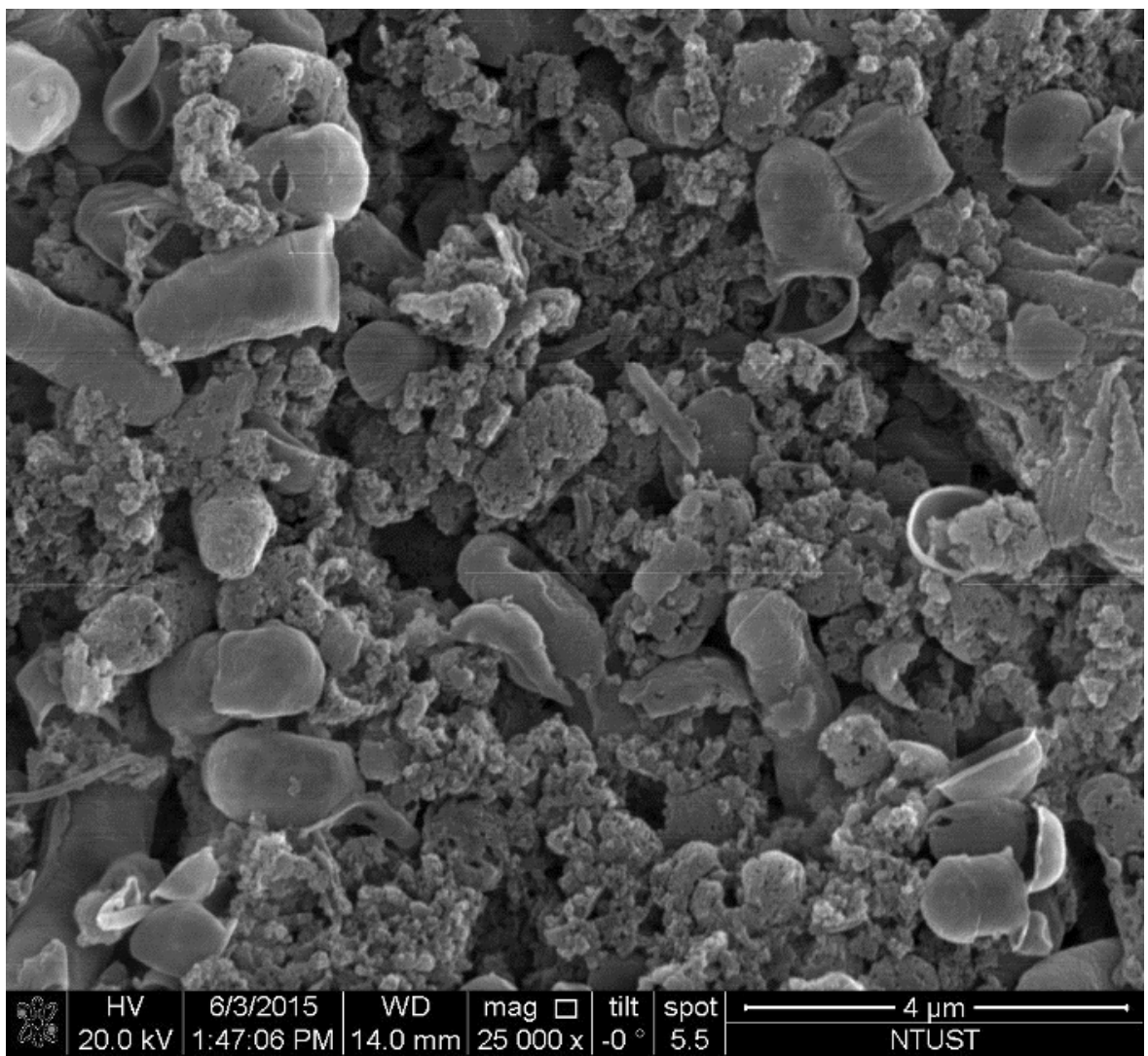

Figure 5: The SEM image of shattered and non-shattered sodium molybdate shells with a grain particle size of $110 \mathrm{~nm}$. Please click here to view a larger version of this figure.

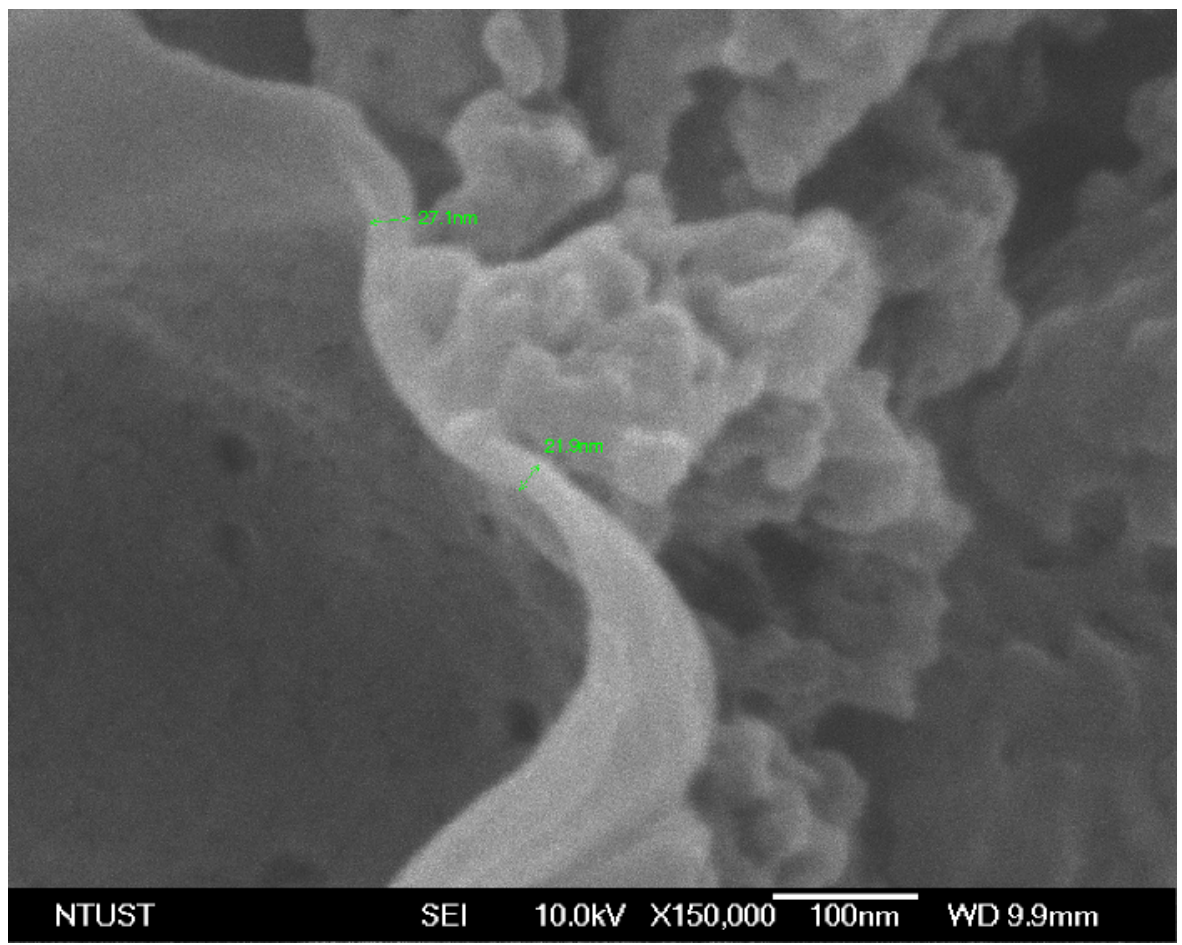

Figure 6: The SEM image of broken hollow shells with a length-to-diameter ratio of 1:1. This structure was made of sodium tungstate excreted by Shewanella algae with glucose as the carbon source. Granules with a size about 40-60 nm hang outside the shell right next to a big hole, while the shell itself is made of granules with a size about $22 \mathrm{~nm}$. Reprinted with permission from ECS J. of Solid State Sci. and Tech., 6(3), N3113 (2017). Copyright 2017, The Electrochemical Society. Please click here to view a larger version of this figure. 


\section{Discussion}

Concerning the self-consistency of the experimental results, the preparation and multiplication of monoclonal bacteria are critical. This experiment, different from the template synthesis experiments ${ }^{15,16}$, employed bioactive gram-negative bacteria. To get a single wall, we chose prokaryotic bacteria instead of eukaryotic bacteria like yeast ${ }^{15}$. To achieve a spherical shape with a length-to-diameter ratio of 1:1, instead of a larger length-to-diameter ratio ${ }^{16}$, we fed bacteria with a much higher concentration of oxyanions to manipulate them to shrink into a spherical shape, making microcapsules with a single, round, and thin wall $(<30 \mathrm{~nm})$.

Since the BME mainly relies on adjusting the concentration of oxyanions to control the metabolism of bacteria, it features two limitations. Firstly, the concentration of oxyanions is limited by the solubility, though the concentration should be as high as possible. Second, most bacterial metabolisms will stop at a temperature over $45^{\circ} \mathrm{C}$ or under $5{ }^{\circ} \mathrm{C}$, respectively the upper and lower bounds of our experiment.

Despite these two limitations, the BME has great potential for making metal oxide materials of practical interest. To substantiate this claim, we are going to try this method to make zirconium microcapsules and iron microcapsules-the former being a good candidate material for artificial bones, and the latter for drug delivery.

\section{Disclosures}

The authors have nothing to disclose.

\section{Acknowledgements}

This work is supported by Ministry of Science and Technology, Taiwan, Republic of China, under grant number MOST 105-2221-E-011-008, and also by Advanced-Connectek Inc., Taipei, Taiwan, ROC under contract number RD Ref. No. 6749 and Dept. Ref. No. 011 through the Graduated Institute of Electro-Optical Engineering, National Taiwan University of Science and technology.

\section{References}

1. Chertok, B., Moffat, B.A., David, A.E., Yu, F., Bergemann, C., Ross, B.D. and Yang, V., Iron Oxide Nanoparticles as a Drug Delivery Vehicle for MRI Monitored Magnetic Targeting of Brain Tumors. Biomaterials. 29(4): 487 (2008)

2. Mansur, C., Pope, M., Pascucci, M.R. and Shivkumar, S. Zirconia-Calcium Phosphate Composites for Bone Replacement. Ceramics Int. 24, $11(1998)$

3. Wang, Y., Arandiyan, H., Jason Scott, J., Bagheri, A., Dai, H. and Amal, R. Recent advances in ordered meso/macroporousmetal oxides for heterogeneous catalysis: a review. J. Mater. Chem. A. 5, 8825 (2017).

4. Kleshch, V.I., Rackauskas, S., Nasibulin, A.G., Kauppinen, E.I., Obraztsova, E.D. and Obraztsov, A.N. Field Emission Properties of Metal Oxide Nanowires J. J. of Nanoelectron. and Optoelectron. 7, 35, (2012).

5. Rinat, R., Ismagilov, R.R., Tuyakova, F.T., Kleshch, V.I., Ekaterina, A., Obraztsova, E.A., \& Alexander, N., Obraztsov, A.N. CVD nanographite films covered by ALD metal oxides: structural and field emission properties. Phys. Status Solidi C. 12(7), 1022 (2015).

6. Mor, G.K., Shankar, K., Paulose, M., Varghese, O.K. and Grimes, C.A. Use of Highly-Ordered TiO2 Nanotube Arrays in Dye-Sensitized Solar Cells. NANO LETT. 6(2) 215 (2006).

7. Lee, J.-H. Gas sensors using hierarchical and hollow oxide nanostructures: Overview. Sensors and Actuators B. 140319 (2009).

8. Poizot, P., Laruelle, S., Grugeon, S., Dupont, L., \& Tarascon Shankar, J-M. Nano-sized transition-metal oxides as negative-electrode materials for lithium-ion batteries. Nature. 407, 496 (2000).

9. Jang, D., Meza, L.R., Greer, F. and Greer, J.R. Fabrication and deformation of three-dimensional hollow ceramic nanostructures. Nature Materials. 12893 (2013).

10. Lazarus, A., Florijn, H.C.B. and Reis, P.M. Geometry-Induced Rigidity in Nonspherical Pressurized Elastic Shells. PRL. 109, 144301 (2012).

11. Vella, D., Ajdari, A., Vaziri, A. and Boudaoud, A. Indentation of Ellipsoidal and Cylindrical Elastic Shells. PRL. 109, 144302 (2012).

12. $\mathrm{Xu}, \mathrm{H}$., Wang, W. Template Synthesis of Multishelled $\mathrm{Cu}_{2} \mathrm{O}$ Hollow Spheres with a Single-Crystalline Shell Wall. Angew. Chem. Int. Ed., 46, $1489(2007)$.

13. Li, B., Shao, X., Hao, Y. and Zhao Y. Ultrasonic-spray-assisted synthesis of metal oxide hollow/mesoporous microspheres for catalytic CO oxidations. RSC Adv. 5, 85640 (2015).

14. Yu, J., Wang, G. Hydrothermal Synthesis and Photocatalytic Activity of Mesoporous Titania Hollow Microspheres. Powder Tech. 301,96 (2016).

15. Xu, G., Zhang, X., Cui, H., Zhang, Z., Ding, J., Wu, J. Facile synthesis of mesoporous SnO2 microspheres using bioactive yeast cell. Powder Tech. 301, 96 (2016).

16. Nomura, T., Tanii, S., Ishikawa, M., Tokumoto, H., Konishi, Y. Synthesis of hollow zirconia particles using wet bacterial templates. Adv. Powder Tech. 24, 1013 (2013).

17. Frankel, R. B., Bazylinski, D. A. Biologically Induced Mineralization by Bacteria. Rev. in Mineralogy and Geochem., 54(1), 95 (2003).

18. Bazylinski, D. A., Frankel, R. B. Biologically Controlled Mineralization in Prokaryotes. Rev. in Mineralogy and Geochem., 54(1), 217 (2003).

19. Lin, P.-H., Huang, Y.-T., Lin, F.-W. Sodium Tungstate and Sodium Molybdate Hollow Microspheres Biologically Controlled Mineralization in Prokaryotes. ECS J. of Solid State Sci. and Tech., 6(3), N3113 (2017). 